\title{
All-Comers Study of Percutaneous Coronary Interventions with Ultrathin Strut Biodegradable-Polymer Sirolimus-Eluting Stents-ORSHINE Registry
}

\author{
Sridhar Kasturi*, Shailender Singh, S. Vijay Kumar Reddy, Kondalrao Gollamandala, \\ Ganesh Mathan, Manikandhar Pendyala, Chandrashekar Challa
}

Sunshine Heart Institute, Secunderabad, Telangana, Hyderabad, India

Email: *sridharkasturi@yahoo.com, *manikandhar@gmail.com

How to cite this paper: Kasturi, S., Singh, S., Reddy, S.V.K., Gollamandala, K., Mathan, G., Pendyala, M. and Challa, C. (2021) All-Comers Study of Percutaneous Coronary Interventions with Ultrathin Strut Biodegradable-Polymer Sirolimus-Eluting StentsORSHINE Registry. World Journal of Cardiovascular Diseases, 11, 319-331. https://doi.org/10.4236/wjcd.2021.117031

Received: March 6, 2021

Accepted: July 6, 2021

Published: July 9, 2021

Copyright ( 2021 by author(s) and Scientific Research Publishing Inc. This work is licensed under the Creative Commons Attribution International License (CC BY 4.0).

http://creativecommons.org/licenses/by/4.0/ (c) (i) Open Access

\begin{abstract}
Current new generation stent technology has made remarkable progress in stent design, structure, and component material to improve its performance in reducing stent thrombosis, and restenosis compared to earlier DES and BMS. Orsiro-Sirolimus eluting stent is new generation ultra-thin strut stent with biodegradable abluminal coating that leaves a polymer free stent after drug release enhances coverage of stent struts and prevents excess neo intimal proliferation. A retrospective data analysis was done to see safety and efficacy of Orsiro in patients treated with ultra-thin DES with Orsiro stents at Sunshine Hospitals, Hyderabad. A total of 331 patients with 525 lesions were treated with 506 Orsiro stents and the major adverse cardiac events (MACE) rate and stent thrombosis (ST) at 2 years' follow-up were analysed. MACE rate was $1.6 \%$ for an average follow-up at 2 years. Out of 2 patients who developed ST, one presented with definite acute stent thrombosis and one with possible, late stent thrombosis and $1.8 \%$ non-cardiac death reported during the follow-up. Despite many patients with complex PCI in the ACS subset, Orsiro reduced significant reduction in MACE rate in all spectrum of coronary artery disease patients with excellent acute and long-term results similar to other established FDA-approved current generations stents.
\end{abstract}

\section{Keywords}

Ultra-Thin Struts, Biodegradable Polymer, Sirolimus-Eluting Stent

\section{Introduction}

Coronary stent technology has made remarkable progress over the last few dec- 
ades in stent design, structure, and component materials. Despite resolving the limitations of BMS, first-generation DP-DES was impeded by the risk of ST. Second-generation DP-DES was developed to address the risk of very late ST associated with first-generation SES and PES. These stents are made up of more biocompatible polymer coatings, less toxic anti-proliferative drugs, and thinner metal alloy stent (cobalt-chromium or platinum-chromium) platforms. Second-generation DP-DES has primarily replaced the preceding generation of devices, and is recognized as the current gold standard for PCI. Despite more biocompatible materials, the permanent polymer coating in second-generation DP-DES remains a driving factor for very late ST. The ongoing issue of very late ST associated with DP-DES has led to the advent of BP-DES [1]. The degradation of the polymer coating removes the potential stimulus for a chronic inflammatory response in the vessel wall. Theoretically, it eliminates the risk of very late ST associated with DP-DES.

Ultrathin Orsiro BP-DES is based on a cobalt-chromium stent platform in a double-helix structure, with helical meanders, longitudinal connectors, and wedge-shaped transitions. The metal alloy cobalt-chromium allows for thinner struts, which provide greater flexibility for effective stent delivery. During stent expansion, the double-helix structure adapts to the vessel curvature without unnatural straightening. This design feature also provides high radial strength to prevent longitudinal compression and foreshortening throughout the stent's entire length. Orsiro BP-DES has a hybrid coating consisting of active and passive components to improve biocompatibility (Figure 1) [2]. The outer layer contains a BIOlute functional coating (Biotronik, Bülach, Switzerland) made from biodegradable PolyL-lactic acid (PLLA) loaded with sirolimus. The PLLA undergoes metabolism via the Krebs cycle into carbon dioxide and water and completely degrades over 12 15 months. Furthermore, the BIOlute functional coating has an abluminal thickness of $7.5 \mu \mathrm{m}$ and a luminal thickness of $3.5 \mu \mathrm{m}$, provides higher drug capacity on the abluminal side than the luminal side. The inner layer contains a ProBIO (Biotronik, Bülach, Switzerland) passive coating which is made from a thin layer (80 $\mathrm{nm}$ ) of silicon carbide which has semi-conductor properties that provide a diffusion barrier between the metal ions and cellular proteins to reduce thrombogenicity and promote re-endothelialisation.

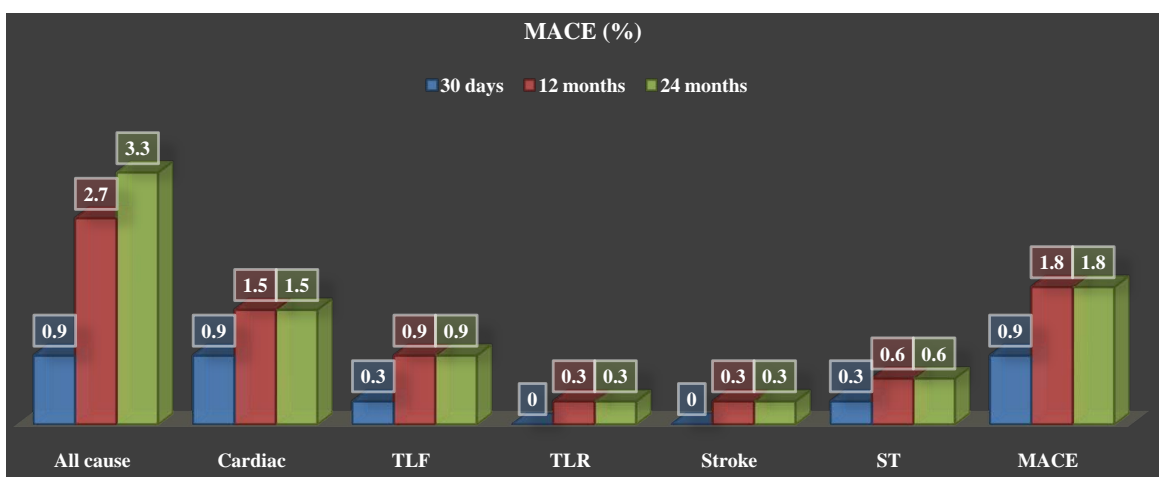

Figure 1. Overall MACE rate up to 24 months' follow-up period. 


\section{Methods}

This is a retrospective study of All-comers data to see safety and efficacy of Ultra-thin strut DES Orsiro in patients who underwent angioplasty with Orsiro stenting at sunshine hospitals Hyderabad, in India between Nov 2015 and Sep 2018. The primary objective of this study is to determine device oriented major adverse cardiac events (MACE) defined as composite of All cause death, cardiac death, TLF, TVR, Stroke, and stent thrombosis (ST). The criteria for inclusion of data for analysis was patients who have undergone PCI with suitable lesions for stent implantation with Orsiro DES and presence of $>1$ coronary lesions in a native coronary artery or SVG that can be covered with single or multiple stents with no limitation to number of treated lesions, number of treated vessels or lesion length.

PCI with Orsiro stenting in each target lesion during interventional procedure was done as per the standard recommended guidelines protocol. All post PCI patients were treated with appropriate medical management, IV Heparin during index procedure, including dual anti platelet therapy (DAPT), high-dose statin, ACE inhibitors, ARBs, $\beta$ blockers, diuretics, and other medications were recommended according to the current guidelines at the discretion of the operating cardiologist. The available data collected as part of standard medical care including demographic information, lesion, stent characteristics and an event for further analysis. The follow up data of the patients were recorded as and when patients attend the clinic and multiple telephonic interviews including communication through SMS and WhatsApp were considered for analysis. Review of MACE and ST was done for an available hospital records includes routine blood investigations, non-invasive tests like ECG, Echocardiogram, stress test and angiogram when necessary [3] [4].

All statistical analysis was performed with SPSS (version 6.0) standard descriptive statistics were used done for baseline lesions, procedural characteristics and for clinical results for all patients. Continues variables were presented as mean \pm $\mathrm{SD}$, range and categorical variables were presented as number and percentages. Descriptive detailed data of the study population and serious adverse events were formulated as per specified time intervals during follow-up.

\section{Results}

\section{Baseline Characteristics and Procedural Results}

The study population included a total of 503 consecutive patients at sunshine hospital, Hyderabad, who underwent single or multi vessel revascularization Nov 2015 and Sep 2018 with 690 number of lesions treated with Orsiro and other DES, but we have considered only 331 patients who underwent PCI exclusively with Orsiro stenting and excluded the patients PCI with Orsiro hybrid stenting (172) to eliminate the influence of other DES on outcomes of Orsiro. Patients baseline demographics are summarized in Table 1, angiographic details were provided in Table 2 and stent characteristics were provided in Table 3 respectively. 
Table 1. Baseline clinical characteristics of study patients $(\mathrm{N}=331)$.

\begin{tabular}{lc}
\hline Clinical Characteristics & \\
\hline Age (years) & $29.7 \pm 10.6$ \\
Male & $210(63.4)$ \\
Hypertension & $175(52.8)$ \\
Diabetes & $67(20)$ \\
Family history of Coronary artery disease & $17(5.1)$ \\
Renal Disease & $224(67.7)$ \\
Good LV function & $72(21.8)$ \\
Mild LV dysfunction & $25(7.5)$ \\
Moderate LV dysfunction & $10(3)$ \\
Severe LV dysfunction & $27(8.2)$ \\
Prior PCI & $16(4.8)$ \\
Prior CABG & \\
Clinical presentation of patients & $151(45.6)$ \\
$\quad$ STEMI & $37(11.2)$ \\
$\quad$ NSTEMI & $22(6.6)$ \\
Stable angina & $121(36.6)$ \\
$\quad$ Unstable Angina & \\
\hline
\end{tabular}

Data are presented as mean $\pm \mathrm{SD}$, number of patients (\%), median (interquartile range). $\mathrm{LV}$, left ventricular; MI, myocardial infarction; PCI, percutaneous coronary intervention; CABG, coronary artery bypass graft; STEMI, ST-segment elevation myocardial infarction; NSTEMI, non ST-elevation myocardial infarction; ACE, angiotensin converting enzyme.

Table 2. Angiographic characteristics of study patients.

\begin{tabular}{lc}
\hline Angiographic characteristics $(\mathbf{N}=\mathbf{3 3 1})$ & \\
\hline Extent of coronary artery disease & $197(59.5)$ \\
SVD & $96(29)$ \\
DVD & $38(11.5)$ \\
TVD & \\
Lesion location $(\mathbf{n}=\mathbf{5 2 5}$ lesions) & $16(3)$ \\
LMCA & $209(39.8)$ \\
LAD & $90(17.1)$ \\
LCX & $160(30.4)$ \\
RCA & $50(9.5)$ \\
Branch Lesions & $161(30.7)$ \\
Long lesion & $82(15.62)$ \\
Total occlusion & $16(3.05)$ \\
LM Bifurcations & $15(2.9)$ \\
Provisional & $1(0.19)$ \\
2 stents Strategy & \\
\hline
\end{tabular}

Data are presented as mean \pm SD, number of patients (\%), median (interquartile range). SVD, single vessel disease; DVD, double vessel disease; TVD, three vessel disease; RCA, right coronary artery; LCX, left circumflex artery; LAD, left ascending artery; OM, obliterate marginal artery; LMCA, left main coronary artery. 
Table 3. Orsiro stent characteristics of study patients $(\mathrm{N}=506)$.

\begin{tabular}{lc}
\hline Stent characteristics & \\
\hline Stent diameter, $\mathrm{mm}$ & $2.94 \pm 0.43$ \\
$\mathbf{2} .5 \mathrm{~mm}, \mathrm{n}(\%)$ & $128(25.3)$ \\
$>\mathbf{2 . 5}$ to $<3.5 \mathrm{~mm}, \mathrm{n}(\%)$ & $262(51.8)$ \\
$\mathbf{3} .5 \mathrm{~mm}, \mathrm{n}(\%)$ & $116(22.9)$ \\
Stent length, $\mathrm{mm}$ & $25.8 \pm 8.25$ \\
$<30 \mathrm{~mm}, \mathrm{n}(\%)$ & $287(56.6)$ \\
$>30 \mathrm{~mm}, \mathrm{n}(\%)$ & $219(43.2)$ \\
No. of Stents in patients $(\mathrm{n}=\mathbf{3 3 1})$ & \\
$\mathbf{1}$ & $198(59.8)$ \\
$\mathbf{2}$ & $100(30.2)$ \\
$\geq 3$ & $33(10)$ \\
\hline
\end{tabular}

The mean age was $59.7 \pm 10.6$ years. A total of 506 Orsiro stents were implanted in 525 lesions during the index procedure. Average implanted stent diameter was $\leq 2.5 \mathrm{~mm}$ in $25.3 \%,>2.5$ to $<3.5 \mathrm{~mm}$ in $51.8 \%$ and $\geq 3.5 \mathrm{~mm}$ in $22.9 \%$ of patients whereas $43.2 \%$ patients had long length $>30 \mathrm{~mm}$ (stent length ranged between $9 \mathrm{~mm}$ and $40 \mathrm{~mm}$ ). Almost majority of patients (59.5) had SVD, DVD in $29 \%$ and TVD in $11.5 \%$ of patients and most of the lesions were located in the LAD (39.8\%), and an average of 1.52 stents were used in 1.6 lesions per patient. Hybrid stenting (combination of Orsiro with other DES) patients were excluded from the study to avoid the influence of other DES on Orsiro clinical outcomes.

This study data includes average median follow-up of 30 days, 12 months and 24 months in 331 patients with exclusive Orsiro implantation (Table 4 \& Figure 1). The cumulative rates of adverse clinical events and overall ST classification are presented in Table 4. MACE rate was calculated for the median follow-up of 30 days, 12 months and 24 months. There were 3 cardiac deaths at 30 days, 5 cardiac deaths at 12 and 24 months, and 1 case of TLF at 30 days, 3 cases of TLF at $12 \& 24$ months', and one case of TVR at $12 \& 24$ months' follow-up were reported. Out of 2 patients who developed ST, one presented with definite acute stent thrombosis and one with possible, late stent thrombosis.

Sub analysis showed more MACE rate in diabetic patients (3.4\%) compared to non-diabetic patients (2.6\%) (Figure 2), in two-vessel and triple vessel disease (5.2\%) compared to single-vessel disease (1.5\%) (Figure 3), and in patients who underwent PCI with two or more stents compared to PCI with a single stent, i.e. $3.75 \%$ VS $2.5 \%$ (Figure 4). No significance difference in MACE were observed in the patients who received single stents $(59.8 \%)$ between short length stents (2.7\%) and long length stents (2.3\%) (Figure 5).

In our study group, low stent thrombosis was observed at 30 days (0.3\%), 12 months $(0.6 \%)$, and 24 months $(0.6 \%)$ probably due to ultrathin stent struts of 
Table 4. Overall major adverse events at 24 months' period.

\begin{tabular}{cccc}
\hline MAE & 30 days & 12 months & 24 months \\
\hline All cause & $3(0.9)$ & $9(2.7)$ & $11(3.3)$ \\
Cardiac & $3(0.9)$ & $5(1.5)$ & $5(1.5)$ \\
TLF & $1(0.3)$ & $3(0.9)$ & $3(0.9)$ \\
TLR & 0 & $1(0.3)$ & $1(0.3)$ \\
Stroke & 0 & $1(0.3)$ & $1(0.3)$ \\
ST & $1(0.3)$ & $2(0.6)$ & $2(0.6)$ \\
MACE & $3(0.9)$ & $6(1.8)$ & $6(1.8)$
\end{tabular}

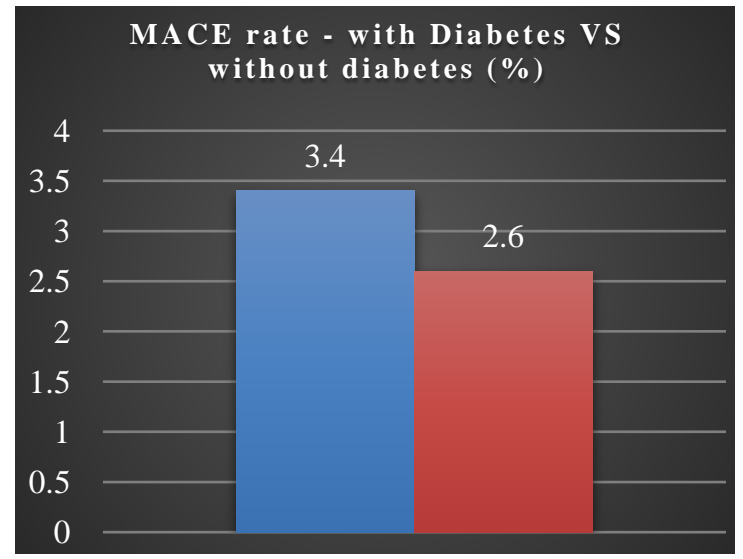

Figure 2. MACE rate with diabetes vs without diabetes.

\section{MACE - SVD VS MVD}

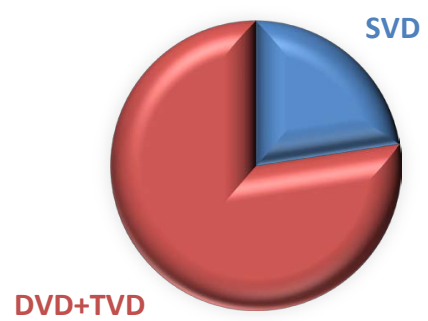

Figure 3. MACE comparison of single vs multi vessel disease.

\section{MACE OF 1 STENT VS > 2 STENTS}

$\square 1$ stent $\square 2$ stents

3.75

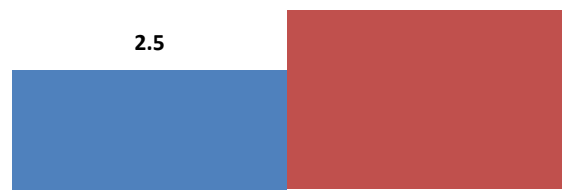

Figure 4. MACE of single vs more than 2 stents patients. 


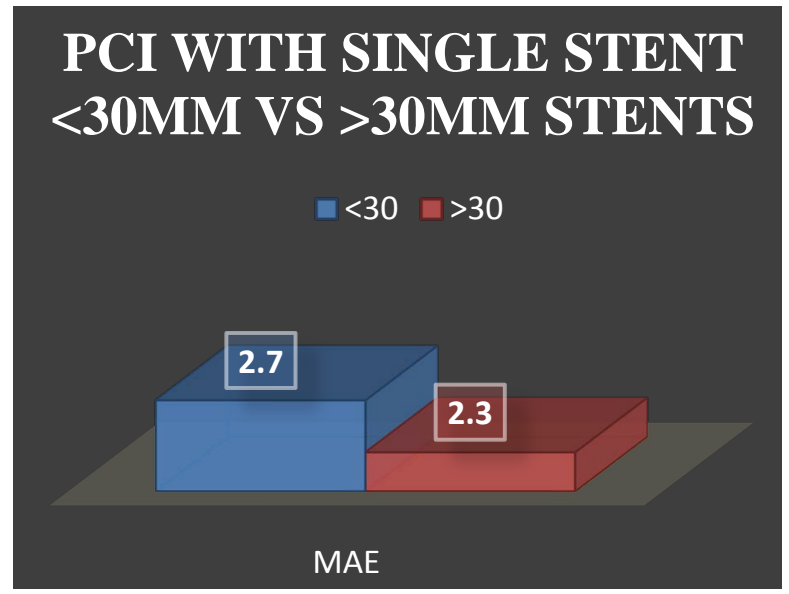

Figure 5. PCI with single stent $<30 \mathrm{~mm}$ stent vs $>30 \mathrm{~mm}$ stents.

Orsiro with biodegradable polymer and standard guideline-directed antiplatelet therapy to the majority of patients (Figure 1). Among 331 patients of study population, 300 patients were treated with DAPT containing Aspirin and Ticagrelor, and 31 patients were treated with DAPT containing Aspirin and Clopidogrel combination therapy for one-year (Figure 6). During subsequent follow-up period, patients were treated with SAPT (Aspirin or Clopidogrel) or DAPT (Aspirin + Clopidogrel) at the discretion of the treating cardiologist.

\section{Discussion}

Our study showed primary and secondary outcomes at 30 days, 12 months, and 24 months' follow-up results are similar to other recently published Orsiro clinical trials results with a reported non-inferior MACE rate in comparison to Xience, Resolute Integrity, and Synergy stents (Table 5). The FDA approved the use of Orsiro BP-DES in patients with CAD based on promising results in recent trials, such as BIOFLOW V [5] and BIOSTEMI [6]. Both of these trials found that Orsiro BP-DES had a significantly reduced risk of target lesion failure, which is a composite of MI, cardiac death, and TLR, compared with Xience EES. A recent meta-analysis of 11,176 patients found that Orsiro BP-DES and second-generation DP-DES conferred equivocal safety and efficacy profiles, with comparable rates of definite or probable ST (odds ratio [OR], 0.77; 95\% CI, 0.53 - 1.12), MI (OR, 0.79; 95\% CI, 0.63 - 1.00), all-cause death (OR, 1.17; 95\% CI, 0.84 - 1.64), and target lesion failure (OR, 0.87).

The primary outcome of the randomized BIONYX (Bioresorbable PolymerCoated Orsiro Versus Durable Polymer-Coated Resolute Onyx Stents) trial showed (Figure 7) non-inferiority of the Resolute Onyx ZES versus the Orsiro SES regarding target vessel failure (TVF) at 12 months in all-comers. During the first year of follow-up, there was a lower incidence of definite or probable stent thrombosis in the Resolute Onyx group [7]. At a 2-year follow-up, Resolute Onyx ZES showed in all-comers excellent safety and efficacy, similar to that of the ultrathin cobalt-chromium-strut biodegradable-polymer Orsiro SES. Among patients in 


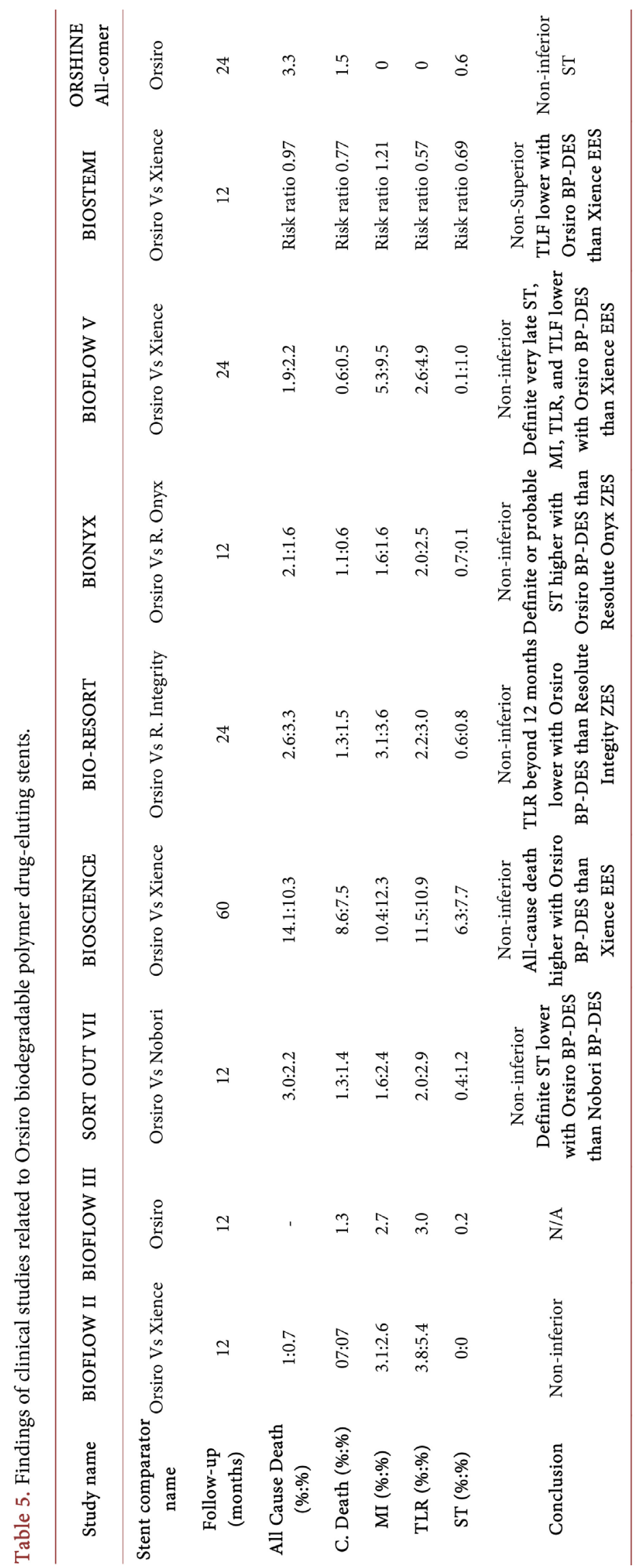




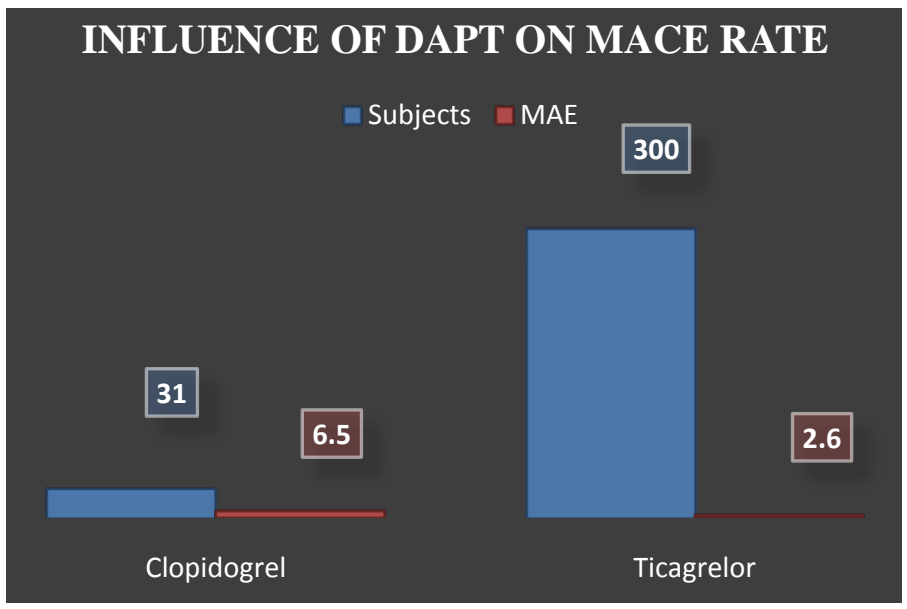

Figure 6. Influence of DAPT on MACE rate.

\section{Primary Endpoint - TVF at 12 and 24 months}

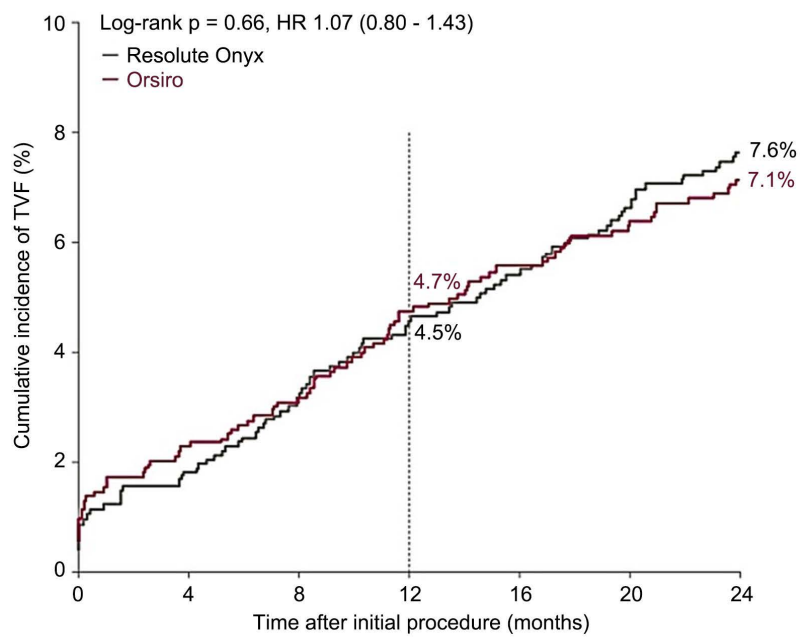

Selected Secondary Endpoints at 12 and 24 months

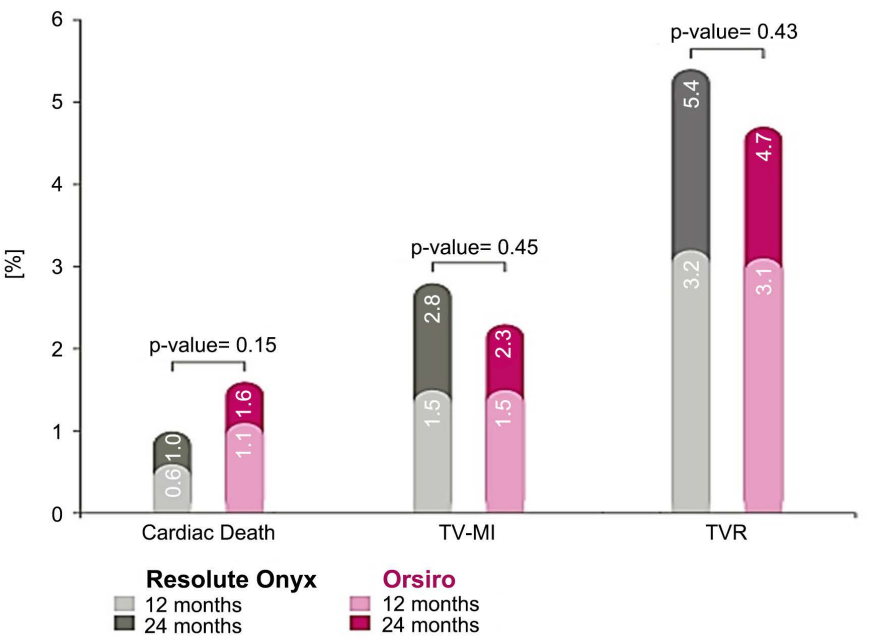

Figure 7. Primary and secondary end-points of BIONYX study.

BIONYX who underwent small-vessel treatment, showed no between-stent differences in the incidence of various clinical endpoints. Our study confirms noninferior results of Orsiro compared to other current-generation DES (Xience, Resolute Onyx, and Synergy) with low MACE rate and stent thrombosis [8]. Randomized BIOFLOW V trial (Figure 8), in which Orsiro outperformed Xience concerning the composite endpoint, target lesion failure, in 1334 patients [5]. BIOSTEMI trial showed a 1-year superiority of Orsiro versus Xience regarding target lesion failure in 1300 patients presenting with ST-segment elevation MI (5.1\% VS 8.1\%) [8]. BIO-RESORT 2 years' follow-up of 3,514 patients, randomized, all-comers trial results showed numerically lower TVF in Orsiro group (6.6\%) compared to Synergy (6.8\%), and Resolute Integrity (8.3\%). Orsiro group also showed numerically lower clinical event rates than both Resolute Integrity and Synergy concerning Target Lesion Failure (TLF), Target Lesion Revascularization (TLR), cardiac death, and definite/probable Stent Thrombosis (ST). Higher 


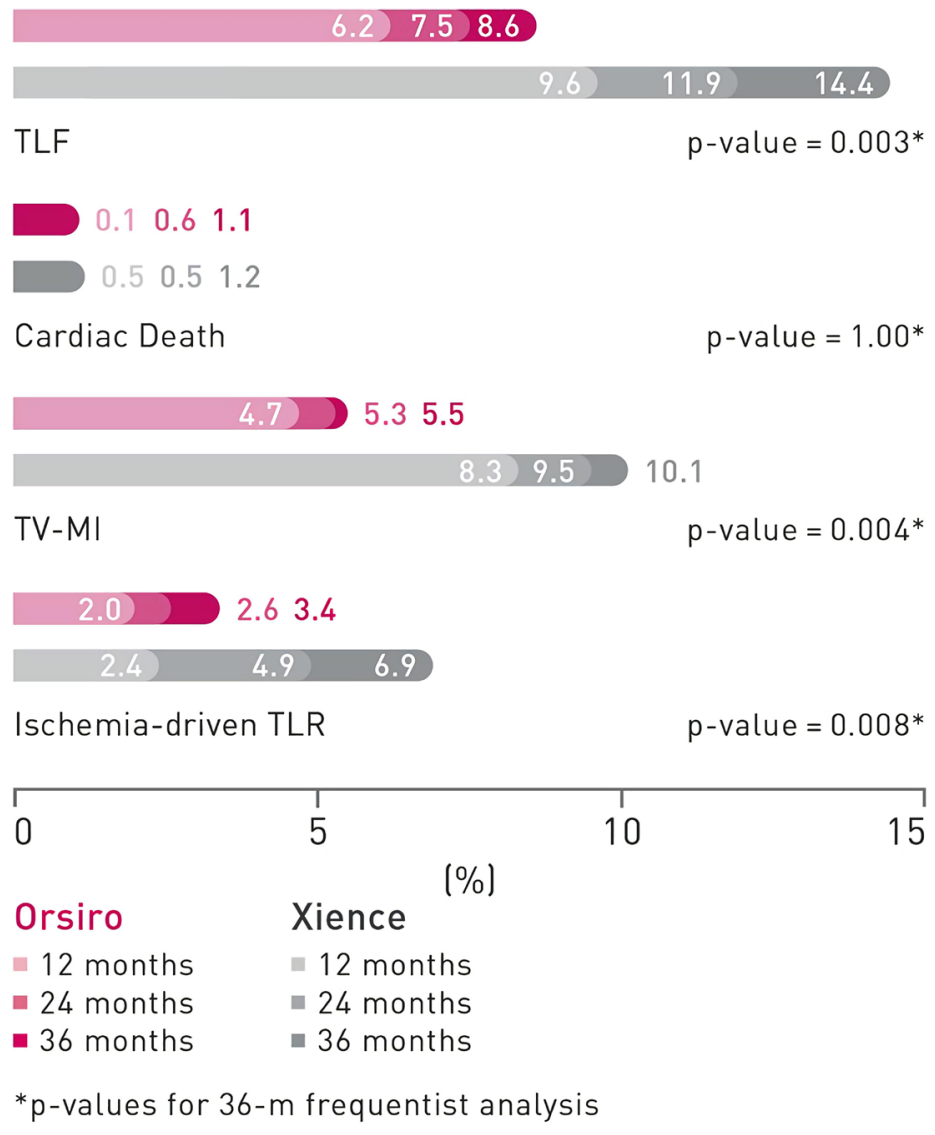

Figure 8. BIOFLOW-V 3 years' follow-up outcomes.

incidence of repeated target lesion revascularizations was observed in patients with small-vessel treated with ZES (Resolute Integrity) versus the ultrathin-strut Orsiro SES [9]. Recently published 3-year follow-up BIORESORT data showed Orsiro has similar outcomes with numerically lower event rates in mainly TVF ( $8.5 \%$ vs $10 \%$ vs $8.8 \%$ ), TLR ( $2.1 \%$ vs $5.3 \%$ vs $4 \%$ ), and ST in the Small vessel subgroup ( $0.6 \%$ vs $1.5 \%$ vs $1.5 \%$ ) compared to Resolute Integrity and Synergy [10].

A randomized controlled (Figure 9) trial of a Three-year clinical outcome of biodegradable hybrid polymer Orsiro sirolimus-eluting stent and the durable biocompatible polymer Resolute Integrity zotarolimus-eluting stent showed TLF occurred in $4.7 \%$ and $7.8 \%$ at 3 years in the O-SES and R-ZES groups, respectively (log-rank $\mathrm{p}=0.227$ ). The occurrence of patient-oriented composite endpoint did not differ between the two groups (15.6\% and $11.3 \%)$ with no significant differences were observed between the two groups in terms of death, MI, repeat revascularization, stroke, and bleeding. A recent meta-analysis of 10 randomized trials (Figure 10) suggested a marginally lower risk of TLF and a significantly lower risk of MI with O-SES than second-generation thicker strut DES at 1 year [11]. The 5-year outcomes of the BIOFLOW-II trial showed a marginally lower risk of stent thrombosis in patients treated with O-SES than in those treated with X-EES $(0.7 \%$ vs. $2.8 \%)$ [12]. In the BIOFLOW V trial of 1 year, $2^{\text {nd }}$ 


\section{TLF rates ${ }^{4}$ out to 12 months ${ }^{1}$}

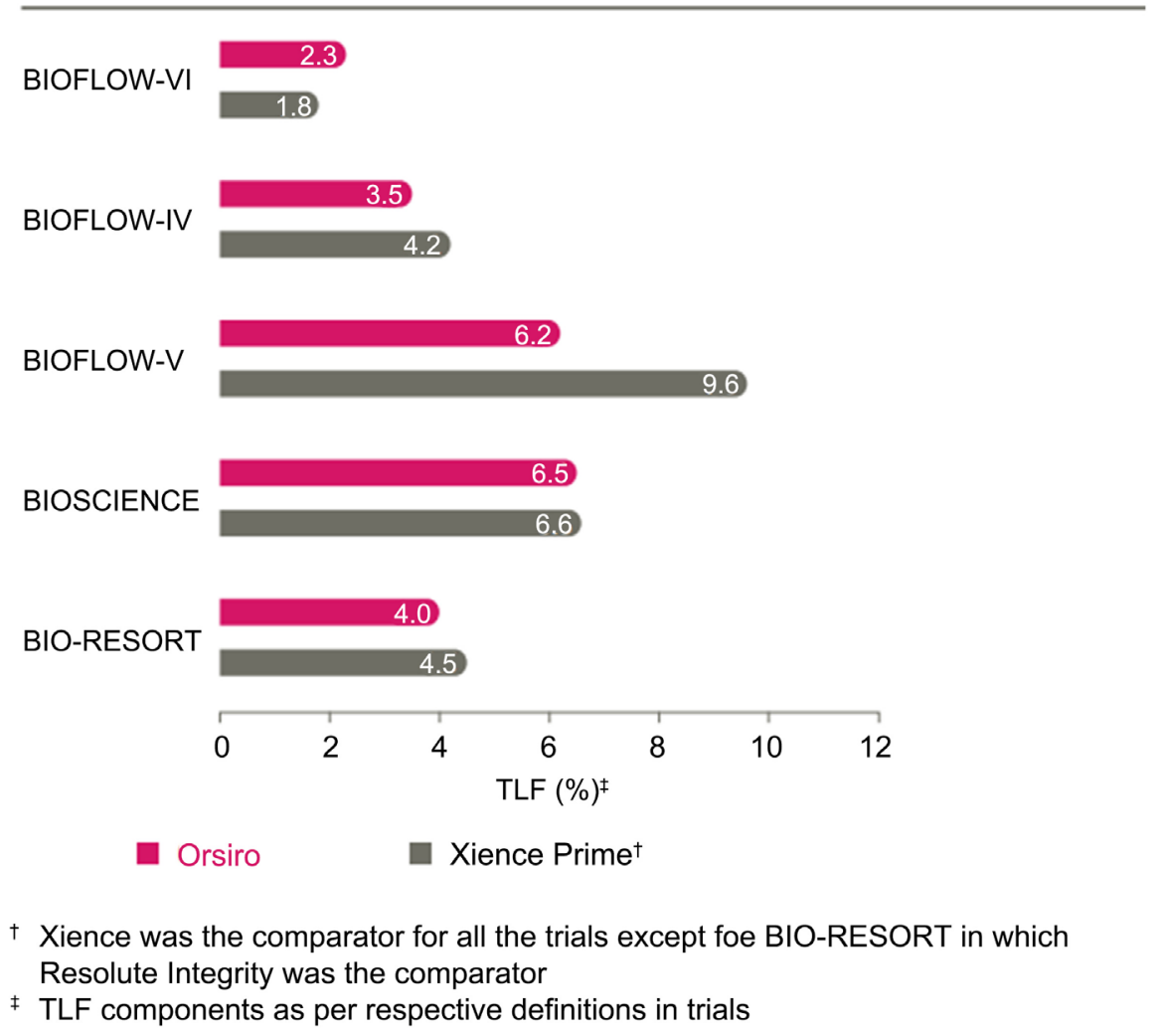

Figure 9. Comparison of TLF rate in \% of various meta-analysis reports.

\section{Meta-analysis of five RCTs comparing Orsiro vs Xience group}

\begin{tabular}{|c|c|c|c|c|c|c|c|c|c|c|c|}
\hline \multirow{3}{*}{$\begin{array}{l}\text { Clinical } \\
\text { outcomes by trial }\end{array}$} & \multirow{3}{*}{$\begin{array}{l}\text { Follow- } \\
\text { up }\end{array}$} & \multirow{3}{*}{$\begin{array}{l}\text { Sample } \\
\text { size }\end{array}$} & \multirow{3}{*}{$\begin{array}{l}\text { Favors } \\
\text { Orsiro }\end{array}$} & \multirow{3}{*}{$\begin{array}{l}\text { Favors } \\
\text { Xience }\end{array}$} & \multirow{3}{*}{$\begin{array}{l}\text { Risk ratio } \\
(95 \% \mathrm{Cl})\end{array}$} & \multicolumn{3}{|l|}{ MI } & \multirow{3}{*}{ 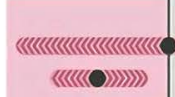 } & \multirow[b]{2}{*}{ (2) } & \multirow[b]{2}{*}{$1.00(0.06-15.9)$} \\
\hline & & & & & & PRISON IV & \multirow{3}{*}{$\begin{array}{l}12-m \\
12-m \\
12-m\end{array}$} & \multirow{3}{*}{$\begin{array}{l}330 \\
1,334 \\
530\end{array}$} & & & \\
\hline & & & & & & \multirow{2}{*}{$\begin{array}{l}\text { BIOFLOW-V } \\
\text { BIOFLOW-IV }\end{array}$} & & & & & $0.56(0.37-0.87)$ \\
\hline$\overline{\text { TLF }}$ & & & & & & & & & «IIU & 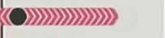 & $1.21(0.51-2.86)$ \\
\hline PRISON IV & $12-m$ & 330 & «IIIK & (I)Iग)। & $1.50(0.69-3.24)$ & BIOFLOW-II & $60-m$ & 452 & 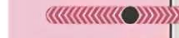 & 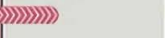 & $0.75(0.33-1.71)$ \\
\hline BIOFLOW-V & $12-m$ & 1,334 & 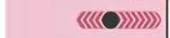 & & $0.65(0.44-0.96)$ & BIOSCIENCE & $60-\mathrm{m}$ & 2,119 & 《(|) & & $0.83(0.65-1.07)$ \\
\hline BIOFLOW-IV & $12-m$ & 530 & «साயU & ग)। & $1.10(0.51-2.38)$ & \multicolumn{3}{|c|}{ Overall $\left(1^{2}=0 \%, p=0.482\right)$} & $\langle 0\rangle\rangle$ & & $0.77(0.63-0.95)$ \\
\hline BIOFLOW-II & $60-m$ & 452 & «सा० & ) & $0.82(0.48-1.40)$ & \multicolumn{3}{|c|}{ Definite/probable ST } & & & \\
\hline BIOSCIENCE & $60-m$ & 2,119 & & & $1.04(0.87-1.25)$ & PRISON IV & $12-m$ & 330 & 《III & & $1.00(0.06-15.9)$ \\
\hline \multicolumn{3}{|c|}{ Overall $\left(l^{2}=38 \%, p=0.169\right)$} & «ाए & & $2-1.20)$ & BIOFLOW-V & $12-m$ & 1,334 & 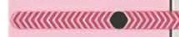 & 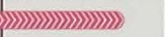 & $0.68(0.15-3.02)$ \\
\hline \multicolumn{3}{|l|}{ All cause death } & & & & BIOFLOW-II & $60-\mathrm{m}$ & 452 & 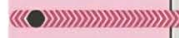 & (2) & $0.17(0.01-4.22)$ \\
\hline PRISON IV & $12-m$ & 330 & 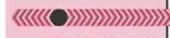 & 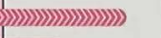 & 0.331 & BIOSCIENCE & $60-\mathrm{m}$ & 2,119 & «स्ण & & $0.81(0.59-1.12)$ \\
\hline BIOFLOW-V & $12-m$ & 1,334 & «सखस्ण & (ग)ागयग) & $0.59(0.20-1.76)$ & \multicolumn{3}{|c|}{ Overall $\left(1^{2}=0 \%, p=0.811\right)$} & 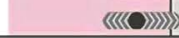 & & $0.79(0.58-1.09)$ \\
\hline BIOFLOW-II & $60-m$ & 452 & 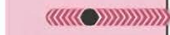 & & $0.52(0.25-1.06)$ & & & & & & \\
\hline BIOSCIENCE & $60-m$ & 2,119 & & «O») & $1.32(1.04-1.67)$ & & & & 0.5 & 2 & 4 \\
\hline \multicolumn{3}{|c|}{ Overall $\left(1^{2}=65 \%, p=0.035\right)$} & 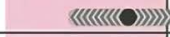 & $\mid(121) \geqslant$ & 0.76 & & & & & & \\
\hline \multicolumn{3}{|l|}{ Cardiac death } & & & & \multirow{3}{*}{\multicolumn{6}{|c|}{$\begin{array}{l}\text { 1. Pilgrim T. etal. Randomized comparison of a novel, ultrathin cobalt-chromium biodegradable polymer } \\
\text { sirolimus-eluting stent with a thin strut durable polymer everolimus-eluting stent for percutaneous } \\
\text { coronary revascularization - final } 5 \text { year outcomes; Presented at: ESC Congress; August 28, 2018; } \\
\text { Munich, Germany. }\end{array}$}} \\
\hline PRISO & $12-m$ & 330 & (en) & गีाग & 0.50 & & & & & & \\
\hline BIOFLOW-V & $12-m$ & 1,334 & 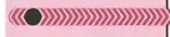 & 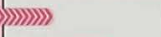 & $0.17(0.02-1.63)$ & & & & & & \\
\hline BIOFLOW-IV & $12-m$ & 530 & 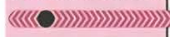 & (|) & $0.25(0.02-2.72)$ & \multicolumn{6}{|c|}{ *Xience and Xience Prime are registered trademarks of Abbott Cardiovascular Systems } \\
\hline BIOFLOW-II & $60-\mathrm{m}$ & 452 & 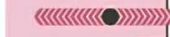 & 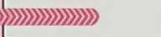 & $0.65(0.18-2.37)$ & \multirow{3}{*}{\multicolumn{6}{|c|}{$\begin{array}{l}\text { Orsiro is a trademark or registered trademark of the BIOTRONIK Group of Companies. } \\
\text { Clinical data conducted with Orsiro, Orsiro Mission's predecessor device can be used to illustrate } \\
\text { Orsiro Mission clinical outcomes. }\end{array}$}} \\
\hline BIOSCIENCE & $60-\mathrm{m}$ & 2,119 & & (I) & $1.06(0.78-1.43)$ & & & & & & \\
\hline \multicolumn{3}{|c|}{ Overall $\left(l^{2}=12 \%, p=0.340\right)$} & «IIIKC & (2) & $0.83(0.51-1.37)$ & & & & & & \\
\hline
\end{tabular}

Figure 10. Meta-analysis of various trails comparing Orsiro Vs Xience stents.

year, and $3^{\text {rd }}$ year follow-up results showed significantly lower stent thrombosisin the patients treated with O-SES compared to X-EES. BIOFLOW V at 3-year 
follow-up data also showed statistically lower patient event rates i.e. $40 \%$ lower TLF rate $(8.6 \%$ vs $14.4 \%) \& 52 \%$ lower TLR rate $(3.4 \%$ vs $6.9 \%)$, and lower ST (1\% vs $2 \%$ ) compared to durable polymers (X-EES) [13].

The BIOSCIENCE trial also showed a marginal interaction of higher risk of stent thrombosis within one year and a lower risk of very late stent thrombosis between 1 and 5 years with O-SES. However, the overall cumulative incidence was similar in both O-SES and durable-polymer EES.

\section{Conclusion}

Orsiro is a sirolimus-eluting ultrathin strut DES with biodegradable polymer, is a well-established current-generation DES with favourable acute and long-term DES results which is non-inferior to presently available current-generation FDA approved drug-eluting stents. Our study reconfirmed efficacy and safety of Orsiro in wide spectrum of coronary artery disease patients including many with ACS which include high percentage of STEMI patients with primary PCI with improved MACE rate in all-comers data involving various subsets of complex PCI.

\section{Conflicts of Interest}

The authors declare no conflicts of interest regarding the publication of this paper.

\section{References}

[1] Jaffe, R. and Strauss, B.H. (2007) Late and Very Late Thrombosis of Drug-Eluting Stents: Evolving Concepts and Perspectives. Journal of the American College of Cardiology, 50, 119-127. https://doi.org/10.1016/j.jacc.2007.04.031

[2] Wu, J.J., Way, J.A. and Brieger, D. (2020) A Review of the Ultrathin Orsiro Biodegradable Polymer Drug-Eluting Stent in the Treatment of Coronary Artery Disease.

[3] Cutlip, D.E., Nakazawa, G., Krucoff, M.W., Vorpahl, M., Mehran, R., Finn, A.V., Vranckx, P., Kimmelstiel, C., Berger, C., Petersen, J.L. and Palabrica, T. (2011) Autopsy Validation Study of the Academic Research Consortium Stent Thrombosis Definition. JACC: Cardiovascular Interventions, 4, 554-559.

https://doi.org/10.1016/j.jcin.2011.01.011

[4] Vranckx, P., Leonardi, S., Tebaldi, M., Biscaglia, S., Parrinello, G., Rao, S.V., Mehran, R. and Valgimigli, M. (2014) Prospective Validation of the Bleeding Academic Research Consortium Classification in the All-Comer PRODIGY Trial. European Heart Journal, 35, 2524-2529. https://doi.org/10.1093/eurheartj/ehu161

[5] Kandzari, D.E., Mauri, L., Koolen, J.J., Massaro, J.M., Doros, G., Garcia-Garcia, H.M., Bennett, J., Roguin, A., Gharib, E.G., Cutlip, D.E. and Waksman, R. (2017) Ultrathin, Bioresorbable Polymer Sirolimus-Eluting Stents versus Thin, Durable Polymer Everolimus-Eluting Stents in Patients Undergoing Coronary Revascularisation (BIOFLOW V): A Randomised Trial. The Lancet, 390, 1843-1852. https://doi.org/10.1016/S0140-6736(17)32249-3

[6] Iglesias, J.F., Muller, O., Heg, D., Roffi, M., Kurz, D.J., Moarof, I., Weilenmann, D., Kaiser, C., Tapponnier, M., Stortecky, S. and Losdat, S. (2019) Biodegradable Polymer Sirolimus-Eluting Stents versus Durable Polymer Everolimus-Eluting Stents in 
Patients with ST-Segment Elevation Myocardial Infarction (BIOSTEMI): A SingleBlind, Prospective, Randomised Superiority Trial. The Lancet, 394, 1243-1253. https://doi.org/10.1016/S0140-6736(19)31877-X

[7] Von Birgelen, C., Zocca, P., Buiten, R.A., Jessurun, G.A., Schotborgh, C.E., Roguin, A., Danse, P.W., Benit, E., Aminian, A., van Houwelingen, K.G. and Anthonio, R.L. (2018) Thin Composite Wire Strut, Durable Polymer-Coated (Resolute Onyx) versus Ultrathin Cobalt-Chromium Strut, Bioresorbable Polymer-Coated (Orsiro) DrugEluting Stents in Allcomers with Coronary Artery Disease (BIONYX): An International, Single-Blind, Randomised Non-Inferiority Trial. The Lancet, 392, 1235-1245. https://doi.org/10.1016/S0140-6736(18)32001-4

[8] Buiten, R.A., Ploumen, E.H., Zocca, P., Doggen, C.J., Jessurun, G.A., Schotborgh, C.E., Roguin, A., Danse, P.W., Benit, E., Aminian, A. and van Houwelingen, K.G. (2020) Thin Composite-Wire-Strut Zotarolimus-Eluting Stents versus Ultrathin-Strut Sirolimus-Eluting Stents in BIONYX at 2 Years. JACC: Cardiovascular Interventions, 13, 1100-1109. https://doi.org/10.1016/j.jcin.2020.01.230

[9] Kok, M.M., Zocca, P., Buiten, R.A., Danse, P.W., Schotborgh, C.E., Scholte, M., Hartmann, M., Stoel, M.G., van Houwelingen, G., Linssen, G.C. and Doggen, C.J. (2018) Two-Year Clinical Outcome of All-Comers Treated with Three Highly Dissimilar Contemporary Coronary Drug-Eluting Stents in the Randomised BIO-RESORT Trial. EuroIntervention, 14, 915-923. https://doi.org/10.4244/EIJ-D-18-00336

[10] Buiten, R.A., Ploumen, E.H., Zocca, P., Doggen, C.J., Danse, P.W., Schotborgh, C.E., Scholte, M., van Houwelingen, K.G., Stoel, M.G., Hartmann, M., Tjon Joe Gin, R.M., et al. (2019) Thin, Very Thin, or Ultrathin Strut Biodegradable or Durable Polymer-Coated Drug-Eluting Stents: 3-Year Outcomes of BIO-RESORT. JACC: Cardiovascular Interventions, 12, 1650-1660. https://doi.org/10.1016/j.jcin.2019.04.054

[11] Kim, S.H., Kang, S.H., Lee, J.M., Chung, W.Y., Park, J.J., Yoon, C.H., Suh, J.W., Cho, Y.S., Doh, J.H., Cho, J.M. and Bae, J.W. (2020) Three-Year Clinical Outcome of Biodegradable Hybrid Polymer Orsiro Sirolimus-Eluting Stent and the Durable Biocompatible Polymer Resolute Integrity Zotarolimus-Eluting Stent: A Randomized Controlled Trial. Catheterization and Cardiovascular Interventions, 96, 1399-1406. https://doi.org/10.1002/ccd.28654

[12] Lefèvre, T., Haude, M., Neumann, F.J., Stangl, K., Skurk, C., Slagboom, T., Sabaté, M., Goicolea, J., Barragan, P., Cook, S. and Macia, J.C. (2018) Comparison of a Novel Biodegradable Polymer Sirolimus-Eluting Stent with a Durable Polymer Everolimus-Eluting Stent: 5-Year Outcomes of the Randomized BIOFLOW-II Trial. JACC: Cardiovascular Interventions, 11, 995-1002. https://doi.org/10.1016/j.jcin.2018.04.014

[13] Kandzari, D.E., Koolen, J.J., Doros, G., Garcia-Garcia, H.M., Bennett, J., Roguin, A., Gharib, E.G., Cutlip, D.E. and Waksman, R. (2020) Ultrathin Bioresorbable-Polymer Sirolimus-Eluting Stents versus Thin Durable-Polymer Everolimus-Eluting Stents for Coronary Revascularization: 3-Year Outcomes from the Randomized BIOFLOW V Trial. JACC: Cardiovascular Interventions, 13, 1343-1353. https://doi.org/10.1016/j.jcin.2020.02.019 